A. Drozhdin

N. Mokhov

R. Soundranayagam

J. Tompkins

\title{
Toward Design of the Collider Beam Collimation System
}

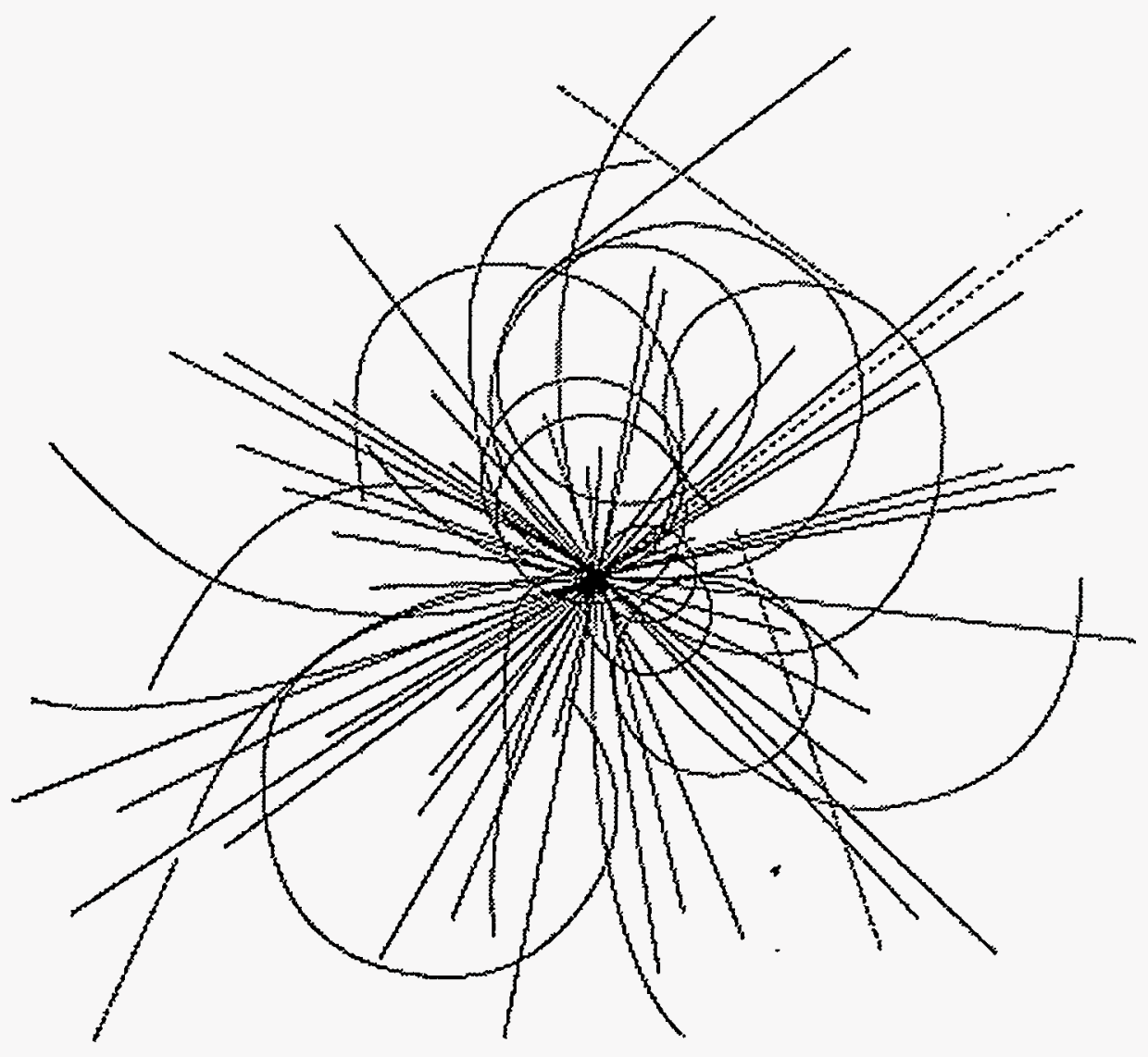

\section{Superconducting Super Collider Laboratory}

APPROVED FOR RELEASE OR

PUBLICATION - O.R. PATENT GROUP BY. QR......... DATE. I.3. 9 . 


\section{Disclaimer Notice}

This report was prepared as an account of work sponsored by an agency of the United States Government. Neither the United States Government or any agency thereof, nor any of their employees, makes any warranty, express or implied, or assumes any legal liability or responsibility for the accuracy, completeness, or usefulness of any information, apparalus, product, or process disclosed. or represents that its use would not infringe privately owned rights. Relerence herein to any specific commercial product, process, or service by trade name, trademark, manufacturer, or othenwise, does not necessarily constitute or imply its endorsement, recommendation, or favoring by the United States Government or any agency thereot. The views and opinions of authors expressed herein do not necessarly state or reilect those of the United States Govemment or any agency thereot.

Superconducting Super Collider Laboratory is an equal opportunity employer. 


\section{DISCLAIMER}

Portions of this document may be illegible in electronic image products. Images are produced from the best available original document. 


\title{
Toward Design of the Collider Beam Collimation System*
}

\author{
A. Drozhdin, N. Mokhov, R. Soundranayagam, and J. Tompkins \\ Superconducting Super Collider Laboratory ${ }^{\dagger}$ \\ 2550 Beckleymeade Ave. \\ Dallas, TX 75237, USA
}

February 1994

\footnotetext{
*To be submitted to the Journal of Nuclear Instruments and Methods in Physics Research.

†Operated by the Universities Research Association, Inc., for the U.S. Department of Energy under Contract No. DE-AC35-89ER40486.
} 


$$
\therefore, \cdots B A
$$




\section{Toward design of the Collider beam collimation system}

A. Drozhdin, N. Mokhov, R. Soundranayagam, and J. Tompkins

Superconducting Super Collider Laboratory,

2550 Beckleymeade Ave., Dallas, TX 75237

A multi-component beam collimation system for the Superconducting Super Collider is described. System choice justification and design requirements are presented. System consists of targets, scrapers, and collimators with appropriate cooling and radiation shielding. Each component has an independent control for positioning and aligning with respect to the beam. Results of beam loss distribution, energy deposition calculations, and thermal analyses, as well as cost estimate, are presented. 


\section{Introduction}

Beam loss in the Collider of the Superconducting Super Collider (SSC) due to $p p$-collisions in interaction points, beam-gas scattering, beam halo scraping, various instabilities, and errors would result in irradiation of conventional and superconducting components of the machine, causing radiation damage, quench, or overheating of equipment [1]. Accidental beam loss can cause damage to the components, resulting in effects ranging from minor to catastrophic. A very reliable beam collimation system is required to protect accelerator equipment against irradiation, to sustain favorable background conditions in the detectors, to maintain operational reliability over the life of the machine, and to reduce the impact of radiation on personnel and the environment. The first full-scale consideration of the Collider scraper system is described elsewhere [2]. The system uses some of the ideas of the Tevatron, UNK, and Large Hadron Collider (LHC) designs. Further studies are described in $[3,4]$.

There are four goals of a beam scraper/collimation system at a superconducting accelerator:

- reduction of beam loss in the vicinity of interaction points caused by beam pipe interactions, which result in background particle fluxes on detector components;

- minimization of radiation impact on personnel and environment by localizing beam loss in the predetermined regions and using appropriate shielding in these regions;

- protection of superconducting magnets and other machine components against irradiation caused by operational beam loss and enhancement of reliability of the machine;

- prevention of quenching of magnets and protection of other machine components from unpredictable abort and injection kicker prefires/misfires and unsynchronized abort.

In the present paper we describe in detail the system components and specify technical requirements. Calculated beam loss rate in the Collider due to beam-gas interaction is about $3 \times 10^{3} \mathrm{p} / \mathrm{m} / \mathrm{s}$ at the baseline parameters. This beam loss is distributed almost uniformly 
along the machine. Local sources such as pp-collisions and scrapers add some peaks to the above "pedestal." Results on beam loss distribution in this paper are presented for those peaks only. Calculations of the source term and energy deposition in the components have been done with MARS12 code [5]; particle tracking in the lattice with STRUCT code [6]; and thermal analysis with ANSYS code [7].

\section{Two-stage collimation system}

The most direct way of collimating a beam of particles is to define the physical aperture with a solid block of absorbing material. Depending upon the material and thickness, a certain fraction of the intercepted beam will survive, either by traversing the whole length of the block or by being scattered out of the block. Fig. 1 shows particle angular distribution at the downstream end of the scraper block for the LHC 8-TeV protons [8]. The number of protons penetrating the whole length of the scraper can be reduced by using a longer block or a "denser" material. Suppression of the outscattered particles is much more difficult. For a given material, the position and width of the peak of the outscattered particle yield depends upon the impact parameter and particle energy. The smaller the impact parameter and the higher the energy, the narrower the peak becomes and the closer it moves to the zero-angle position.

The principal scheme of a two-stage collimation system is shown in fig. 2. The transverse position of outscattered protons and of protons traversing the entire block is almost the same, but they have different angular distributions. Consequently all these particles fall along a vertical straight line in the phase space, as shown in fig. 2. After rotating about $10^{\circ}$ in the phase advance, the segment of line corresponding to positive angle can be efficiently intercepted by a secondary collimator. For a segment corresponding to outscattered particles (negative angles), it is necessary to place a secondary collimator at about $150^{\circ}$ in phase advance downstream of the first collimator. The Tevatron uses only 
one secondary collimator, and as for the LHC at CERN both the $10^{\circ}$ and $150^{\circ}$ secondary collimators have been proposed.

A two-stage collimator scheme, in principle, can intercept most of the outscattered protons at the first turn, provided the secondary collimator jaw is in the same transverse position as that of the primary collimator with respect to the closed orbit. The major problem with such a system is the alignment of the collimator jaws with respect to the closed orbit of the circulating beam. Alignment of these jaws with respect to each other as well as with respect to the beam orbit becomes critical, as the position of the jaws will also limit the physical aperture of the machine. Moreover, a heavy shielding around all these locations is required to prevent groundwater activation and equipment irradiation.

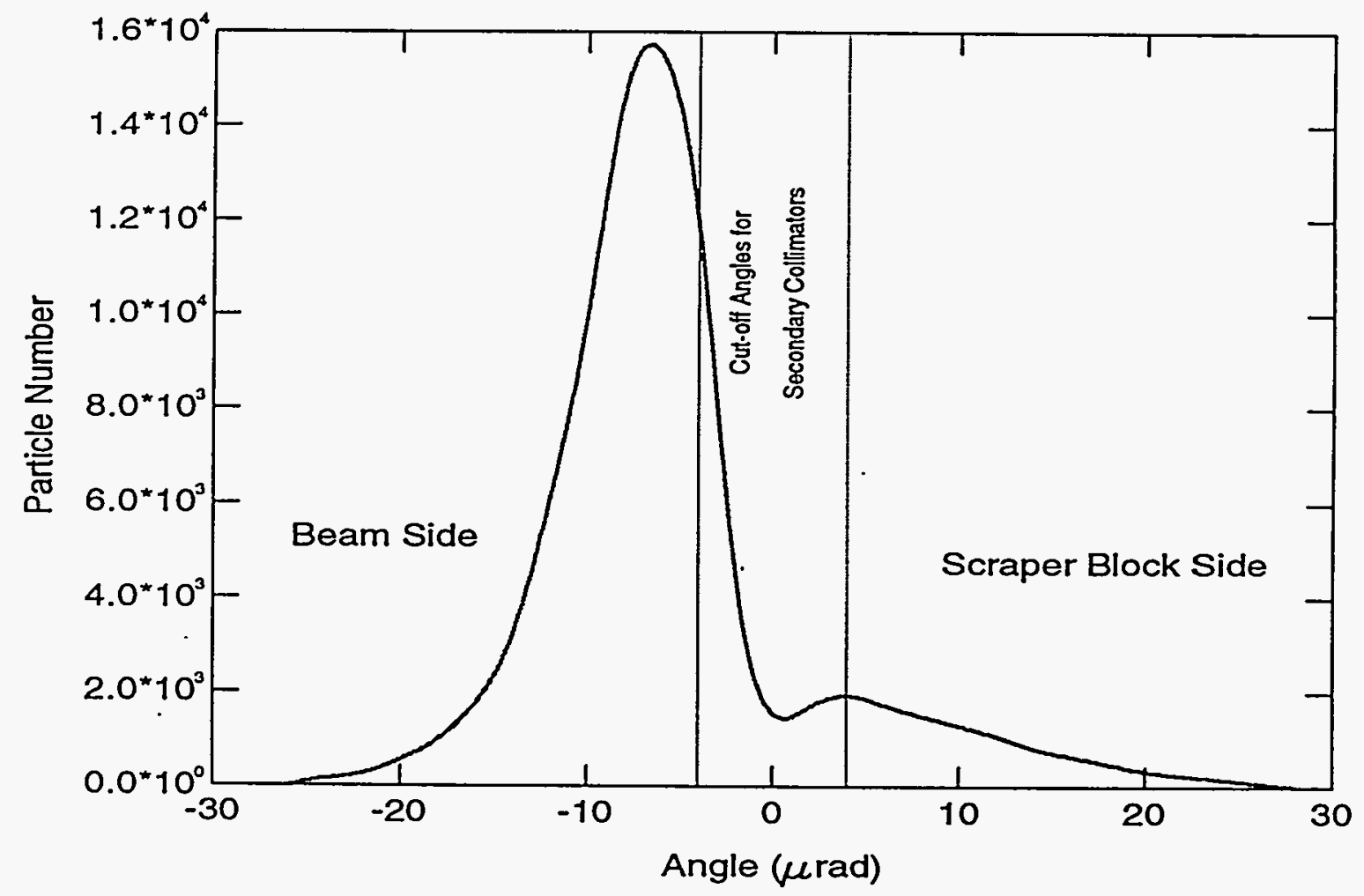

-Fig. 1. Particle density angular distribution at the downstream end of the scraper block for the LHC 8-TeV protons. 


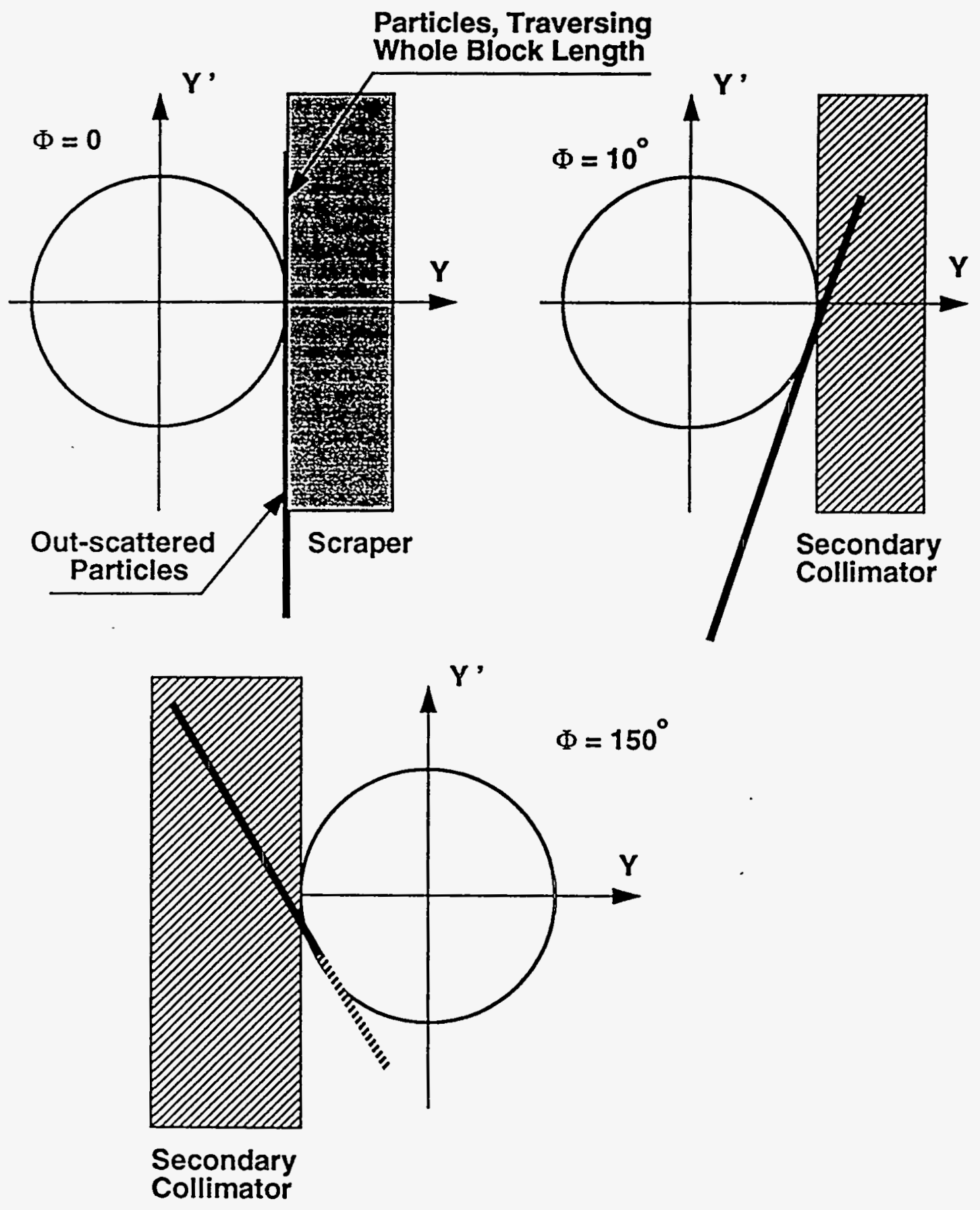

Fig. 2. Principal scheme of a two-stage collimation system. 


\section{SSC choice: target-scraper and collimators}

The system accepted for the SSC consists of a scattering target made of tungsten and associated scraper followed by a few collimators [2]. Horizontal and vertical scrapers are positioned at about $10 \sigma$ and the collimators are positioned at about $20 \sigma$, where $\sigma$ is one standard deviation of Gaussian transverse beam intensity distribution. The scattering target associated with each scraper is positioned from $0.5 \sigma$ to $2 \sigma$ closer to the beam orbit than the scraper (fig. 3). A target-scraper combination eliminates the need of the secondary scrapers at $10^{\circ}$ and $150^{\circ}$ downstream of the main scraper. As the halo particles pass through the scattering target, some of them will get an angular deflection, increasing their amplitude of betatron oscillations, and they will be intercepted by the scraper within the next few turns. Other particles undergo multiple passes through the target before being intercepted by the scraper. The real effect of the scattering target is that the impact parameter distribution of the particles intercepted by the scraper is much broader and thus results in a smaller amount of outscattered protons (up to 10 times lower integrated beam loss downstream of the scraper [2]) and lower energy deposition density in the scraper material. The alignment requirements are almost 10 times softer [2] compared to the two-stage collimation scheme, where these are on a scale of a few microradians.

The actual impact parameter distribution depends on the target thickness, position offset of the target from the scraper position, and the $\beta$-function at the target location. Increase of each parameter value results in more favorable distribution and higher efficiency. However, increase in target thickness and offset can result in more secondaries produced through nuclear interactions within the target, causing irradiation of downstream equipment. Another limit is due to heat generated in the target and conductivity of heat through the target supports. Therefore, optimization of the above parameters is rather crucial. 

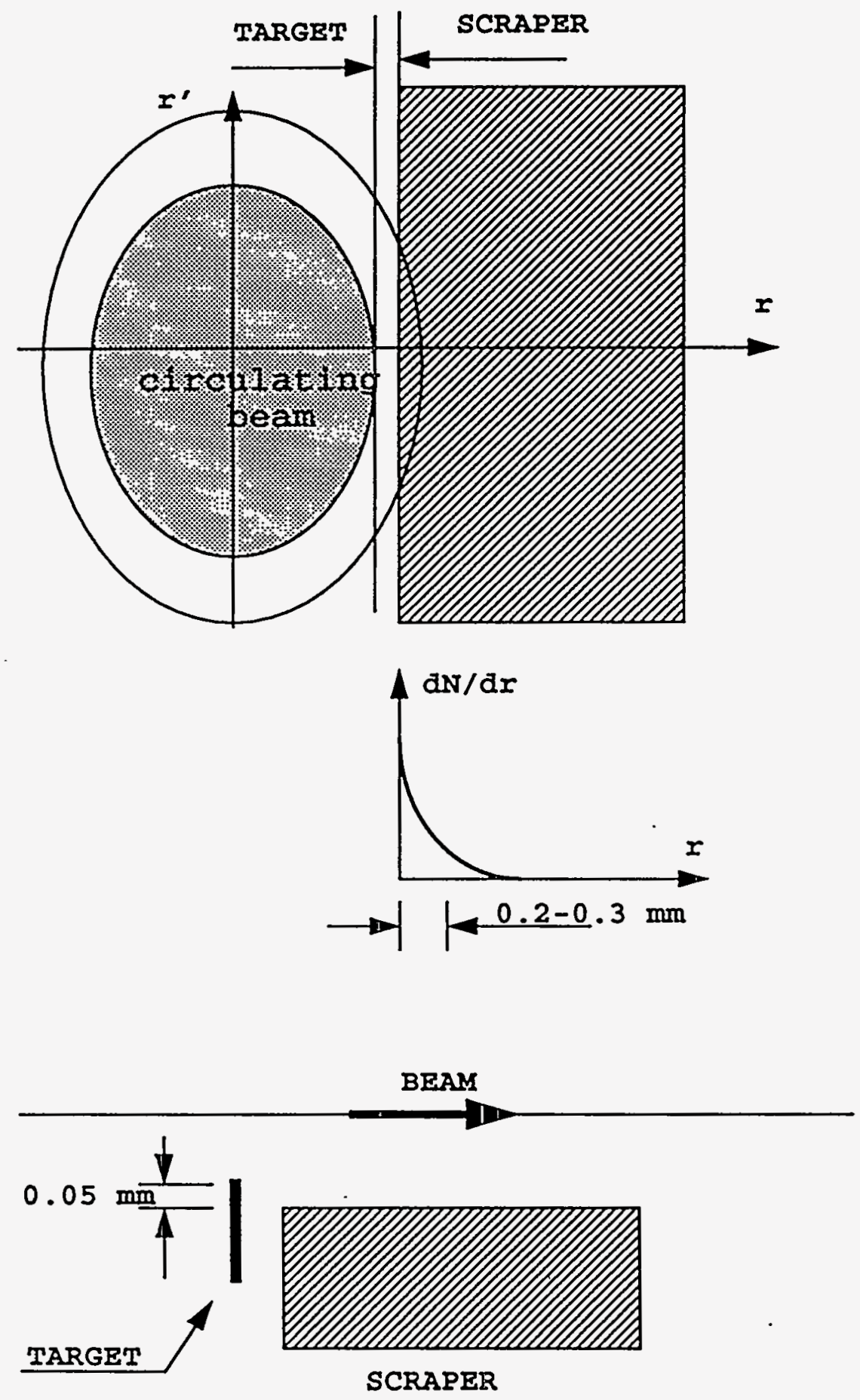

Fig. 3. Principal scheme of the scrapers target assembly. 
Increase of betatron amplitude of the protons scattered by the target is very small compared to the physical aperture of the machine (1-2б); therefore, they pass around the accelerator without any loss until they reach the scraper. This procedure allows the impact parameter distribution at the scraper face to span up to 200-300 $\mu \mathrm{m}$ (fig. 4) instead of a few $\mu \mathrm{m}$ in the absence of target. As a result, the peak energy deposition in the scraper is about 2.5 times lower, and the yield of outscattered particles is lower by a factor of 10 [2]. From our simulation studies, a 1-mm-thick tungsten target with target-scraper offset of about $0.05 \mathrm{~mm}$ appears to be suitable for the $2-20 \mathrm{TeV} \mathrm{SSC}$ beam. About $4 \%$ of halo protons have nuclear interactions in the target. Density distribution of protons going out of the scraper is presented in fig. 5 . About $2 \%$ of the protons entering the scraper jaw go out of it. Here we mean protons with momentum $\mathrm{p}>0.7 \mathrm{p}_{0}$, where $\mathrm{p}_{0}$ is the beam momentum. Only these protons contribute to a long-distance beam loss, most of which is intercepted by the collimators.

Amplitude distribution of particles going out of the scraper is shown in fig. 6. Only large-amplitude particles with amplitude $>25 \sigma$ and off-momentum protons can hit the superconducting magnets at long distances from the scraper. The yield of these particles depends on scraper material and length. The number of particles leaving the scraper with an amplitude larger than $25 \sigma$ is about 3 times lower for the 1.2-m-long copper scraper chosen in our design [2] than for a 0.6 -m-long scraper (fig. 7). A set of horizontal and vertical collimators in the West Utility is used to intercept particles going out of the scraper (see fig. 8). Positions of circulating beam and outscattered particles at the entrance to these collimators are shown in fig. 9. Collimators, installed at the $20 \sigma$ position, can intercept most of the large amplitude protons. About half of the particles are intercepted by the Lambertson's shadow (SSWUT) and the first collimator (fig. 10). One more collimator placed downstream intercepts most of the remaining particles. Only $0.1 \%$ of particles (from particles going out of the scraper) passing through the dogleg and the set of collimators in the West Utility has amplitudes higher than $25 \sigma$, and only these particles can irradiate the 
superconducting magnets far away from the West Utility. A corresponding beam loss rate in the low- $\beta$ quads of the Interaction Regions (IRs) is equal to $1 \times 10^{4} \mathrm{p} / \mathrm{m} / \mathrm{s}$.

About $60 \%$ of protons escaping the scraper come back to the scraper during the next few turns. All other protons are intercepted by the collimators in the West Utility and East IRs (see next section). The main advantages of the SSC scheme compared to the two-stage scheme are:

- there is only one place with drastic restriction of accelerator aperture (scraper position);

- only this region needs a large amount of shielding and a dogleg structure;

- a thin target is used to increase the average impact parameter of halo particles at the scraper, significantly decreasing the yield of outscattered protons (i.e., total beam loss in the accelerator), scraper jaws overheating, and mitigating requirements to scraper alignment;

- beam scraping efficiency is independent of accelerator tuning.

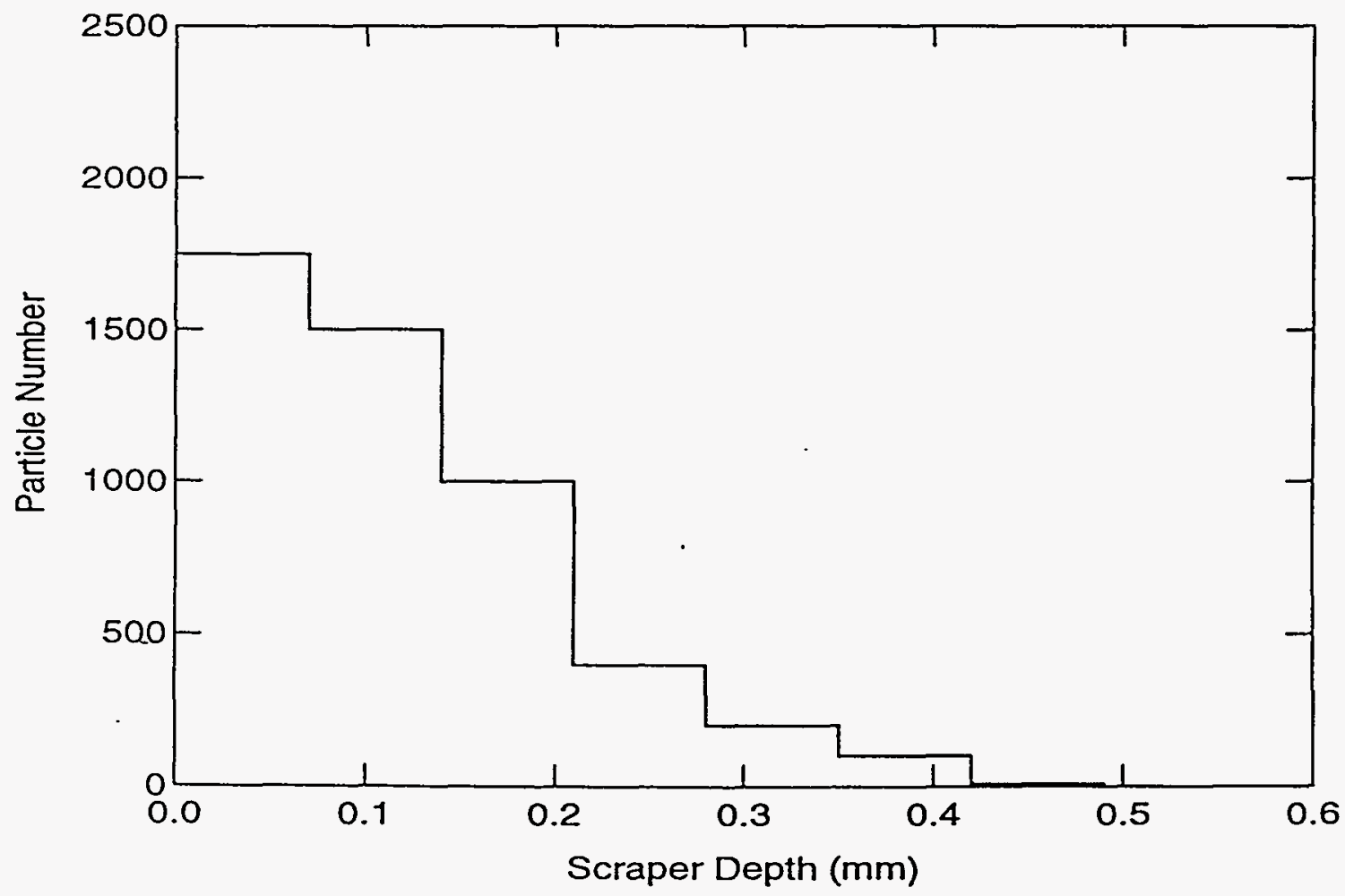

Fig. 4. Particle distribution at the scraper for the Collider $20-\mathrm{TeV}$ protons. 


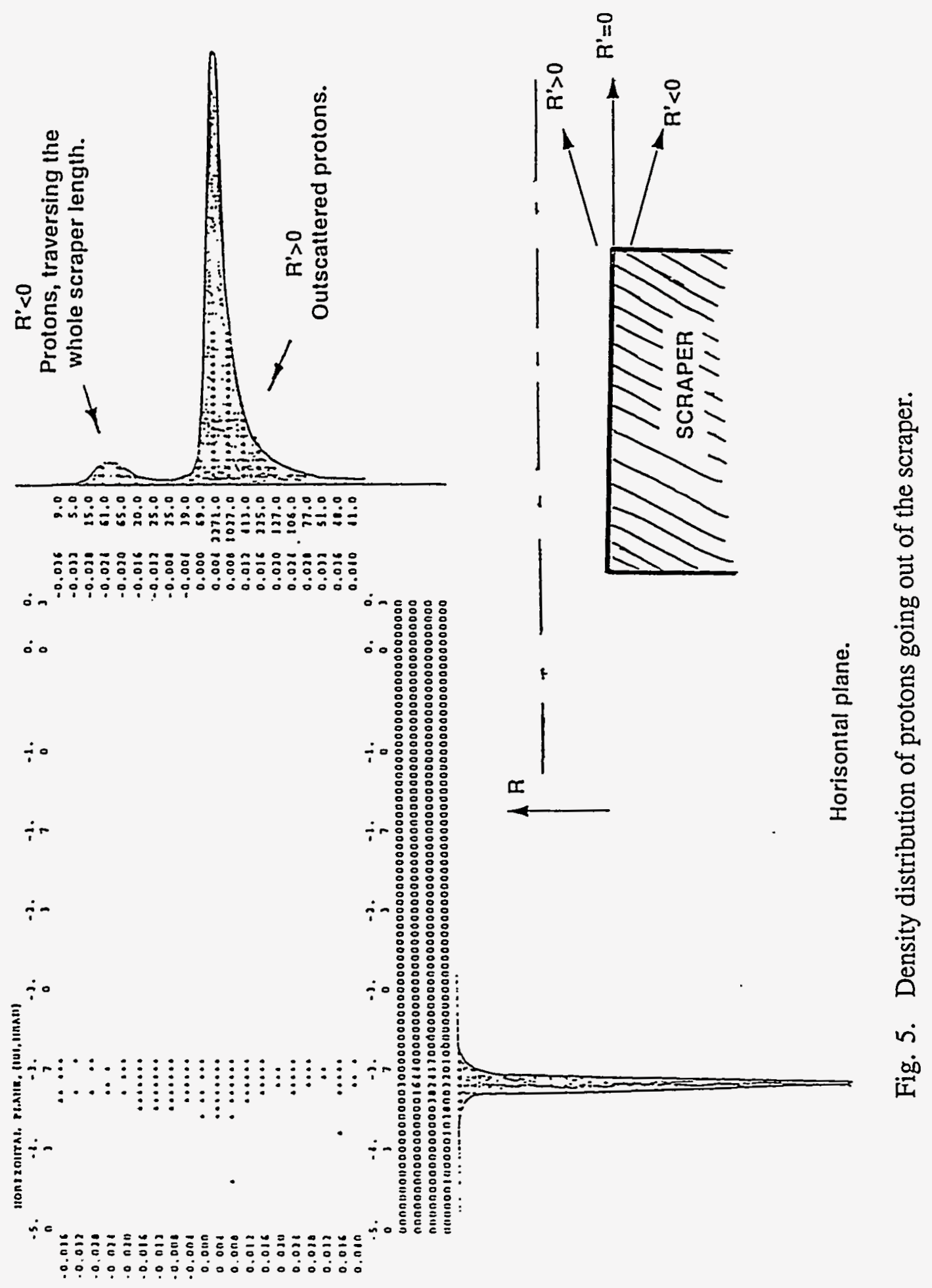




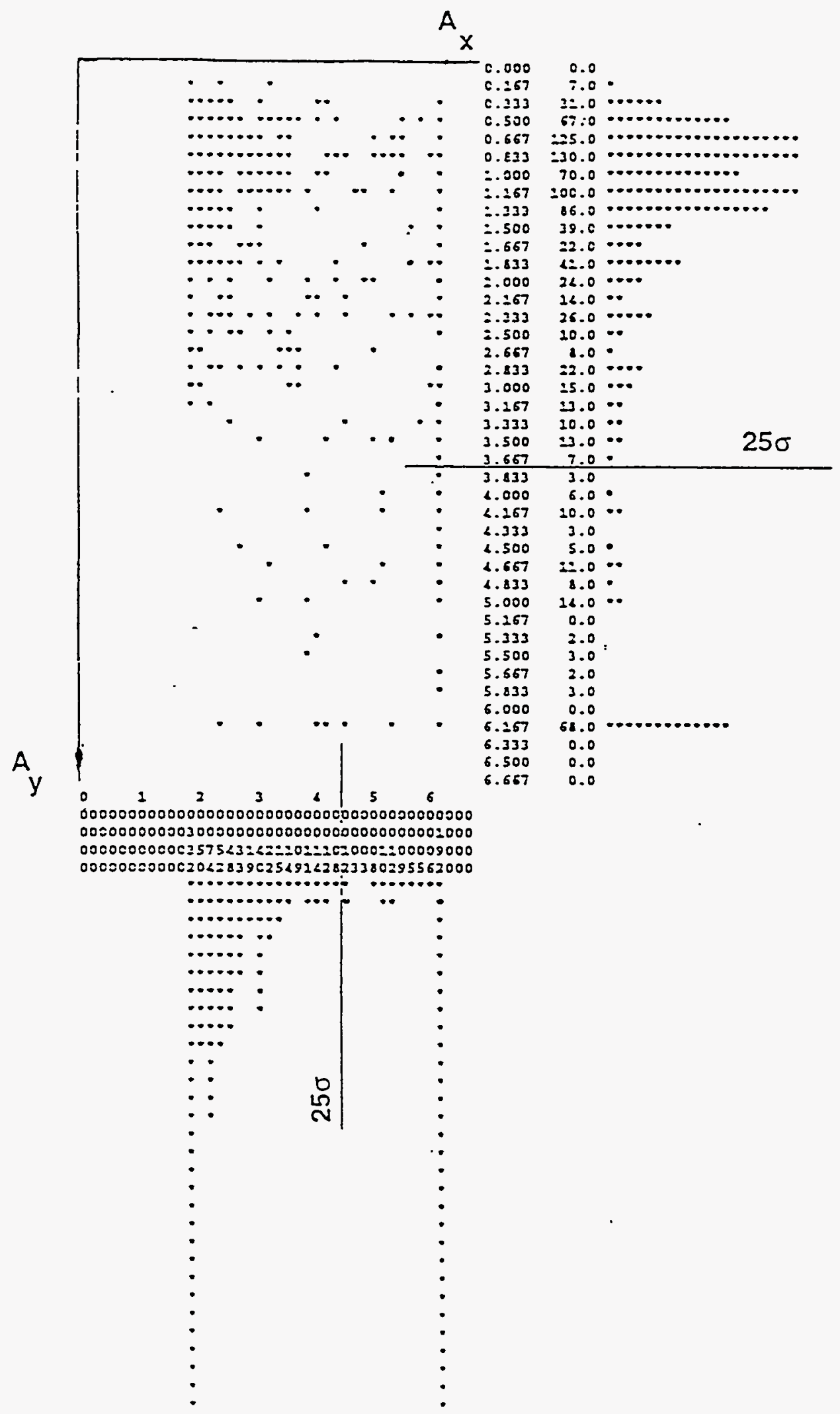

Fig. 6. Amplitude distribution of particles going out of the scraper. 


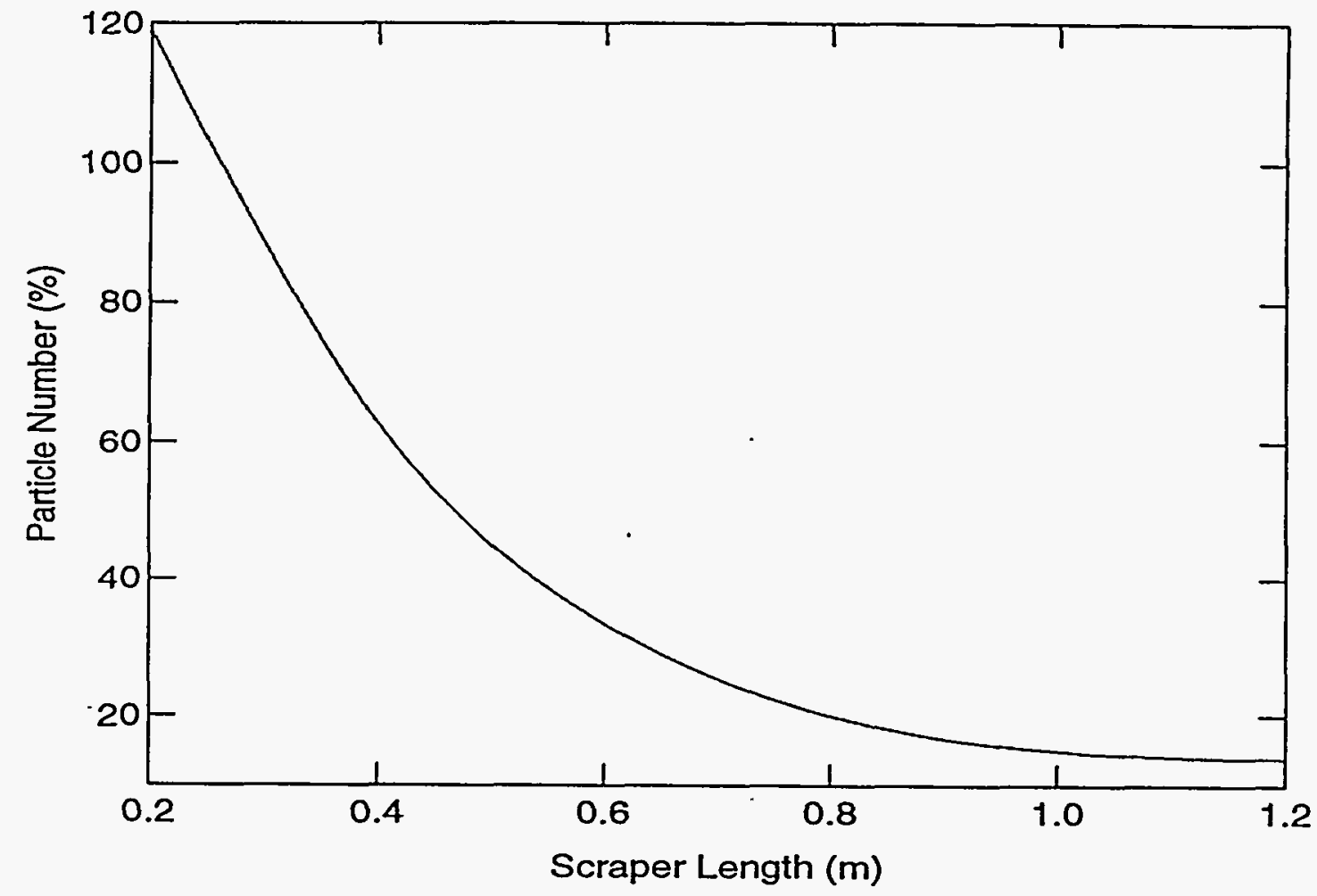

Fig. 7. Number of particles leaving the scraper with amplitude $>25 \sigma$ as a function of copper scraper length. 


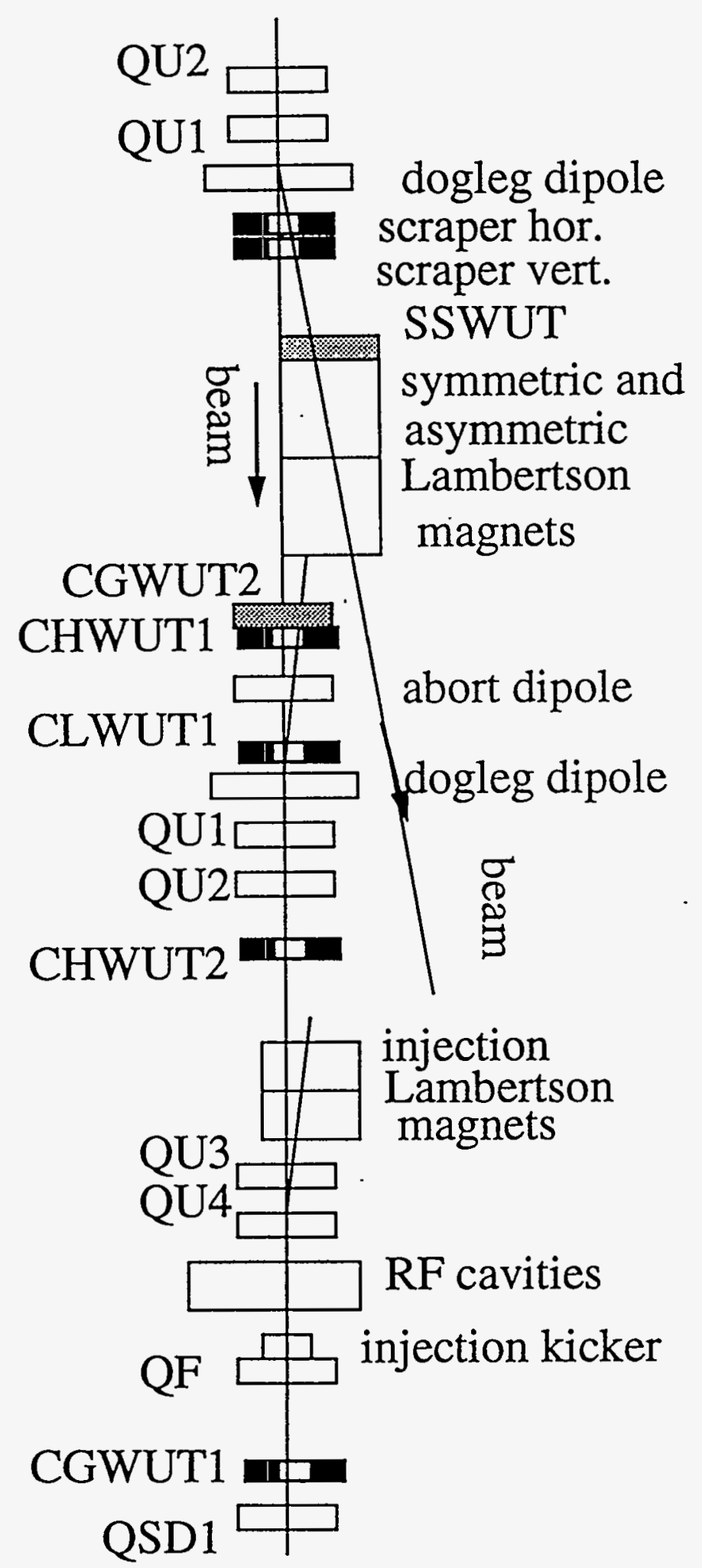

Fig. 8. Scraper and collimator positions in the Collider West Utility. 

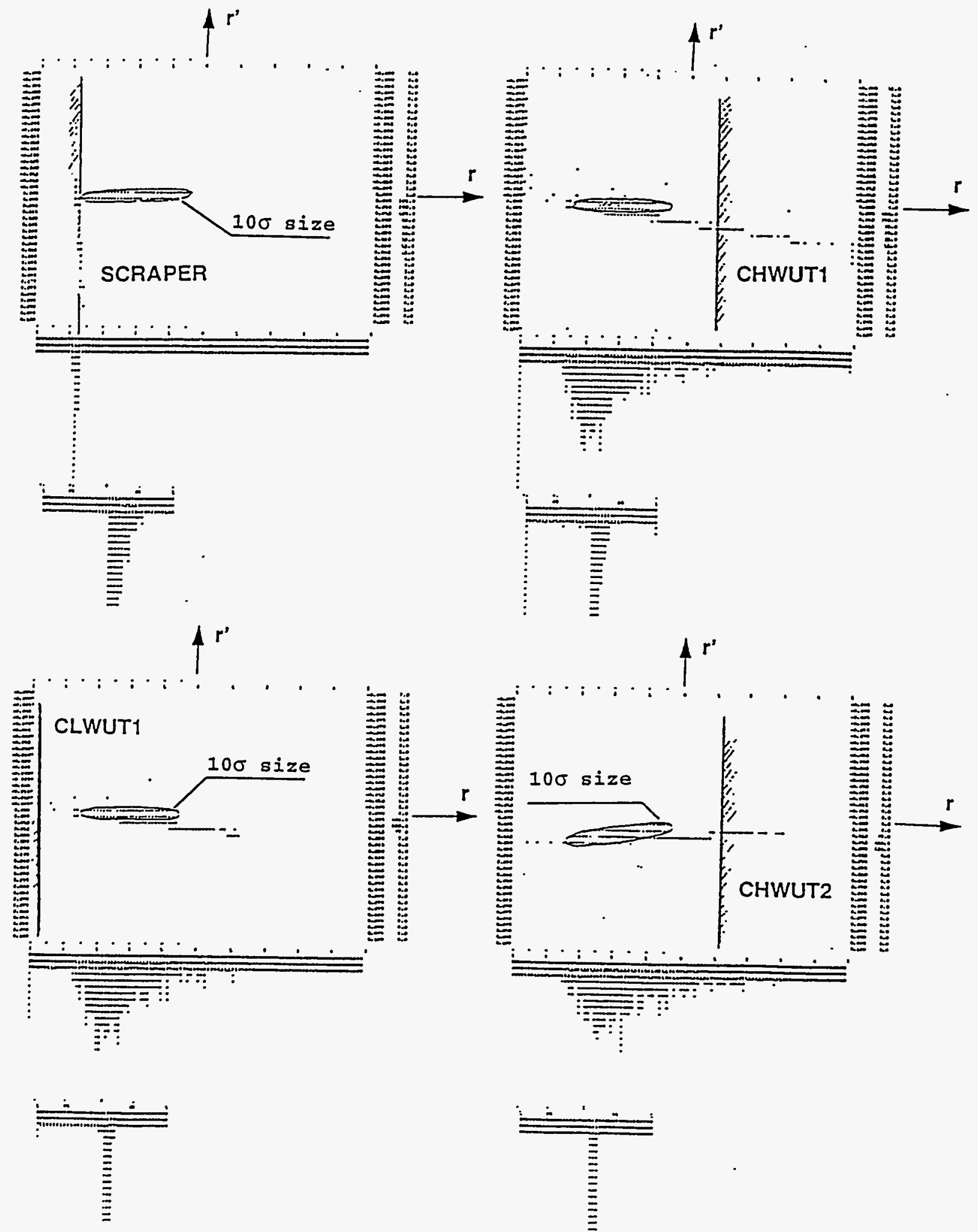

Fig. 9. Positions of circulating beam and outscattered particles at the entrance of the West Utility collimators. 


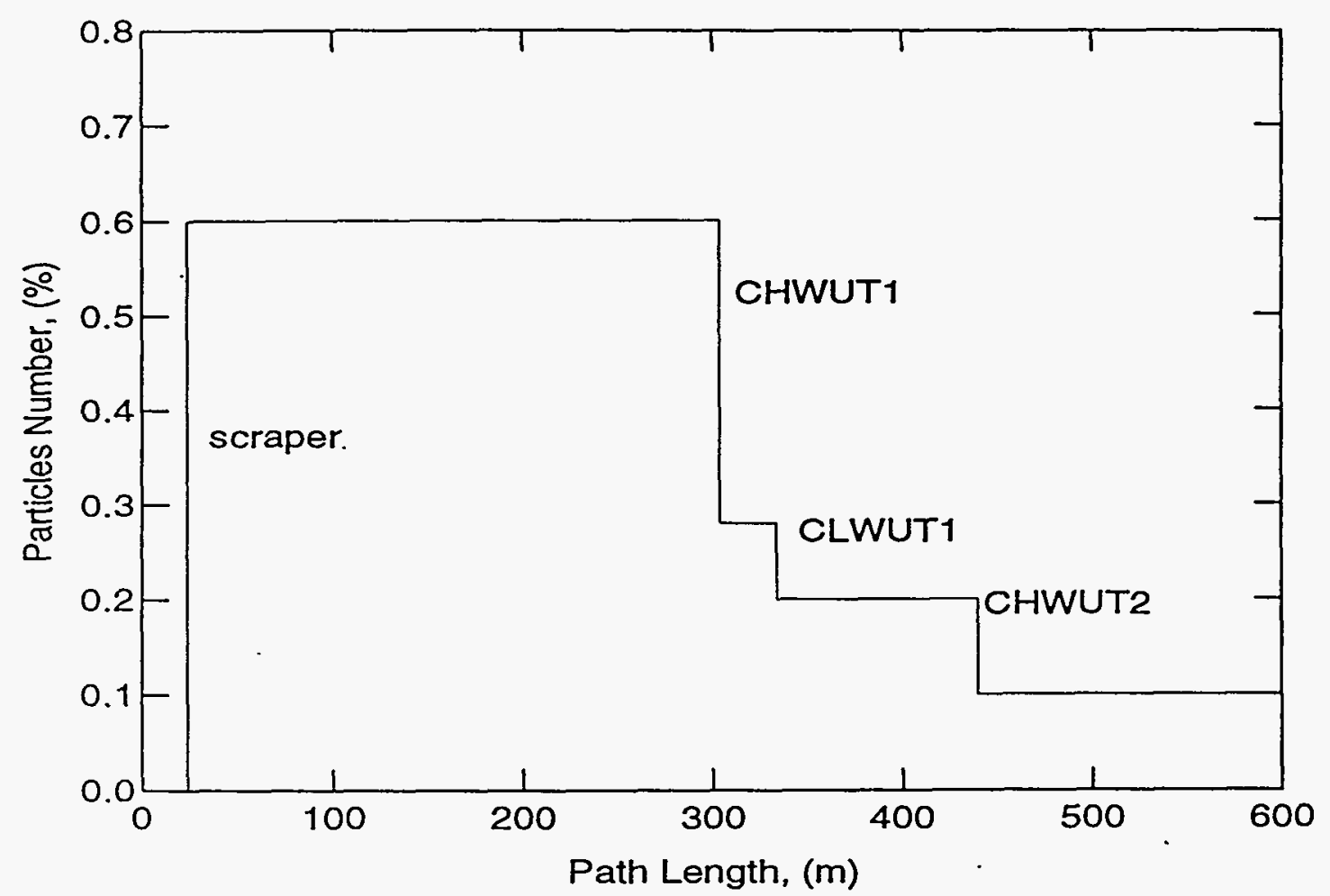

Fig. 10. Number of large amplitude protons intercepted by Lambertson's shadow and collimators in the West Utility.

\section{Design requirements}

The expected scraping rate is rather high (table 1): up to $1 \%$ of intensity at injection and beginning of acceleration, up to $2 \%$ over the first $15 \mathrm{~min}$ of the flattop, and then up to $10 \%$ during collisions ( $24 \mathrm{~h}$ ) [9]. The proposed scraper/collimator system should be compatible with such a rate, so all components must be carefully designed. The primary components of the system, the scrapers, are situated in the Collider West Utility section. $\beta$-functions in this region are shown in fig. 11. The straight section between central quads (QUIs in fig. 8 ) is a very convenient position for scrapers. $\beta$-functions are rather high (about $600 \mathrm{~m}$ in radial (horizontal) and $400 \mathrm{~m}$ in vertical planes) for efficient beam scraping. The distance between quads is approximately $400 \mathrm{~m}$, which is enough for a dogleg structure. Actually this location is used for the beam abort system, whose components match the scraper system dogleg needs. For each ring, the system (fig. 8) consists of horizontal and vertical 
scrapers, four collimators, and a shadow septum. Collimators CHWUT1 and CLWUT1 (table 2) intercept neutrals, negative particles, and low-energy positive particles going out of the scraper jaws. Collimator CHWUT2 is used to intercept protons with $p>0.7$ po. The shadow septum SSWUT is a replica of the downstream Lambertson magnet but is made of graphite to protect the magnet during abort kicker failures. The collimator CGWUT1 is a graphite collimator to protect the downstream magnets during injection kicker failures.

Table 3 shows the power deposited in targets, scrapers, shadow, and collimators of the Collider beam collimation system for the three regimes indicated in table 1 . The collimators are split into two groups, with a difference of about a factor of two in energy absorbed. Specific parameters considered in the design requirements of each major component are:

Target. A 1-mm-thick tungsten scattering target is sufficient to increase the average impact parameter and thus increase efficiency of the scraper to the required level. Energy deposited in the target is also low enough for its support system to conduct the heat away instead of requiring an active cooling system that would make the whole system too complicated. For practical reasons we have proposed scattering targets of varying thicknesses of $0.5-5 \mathrm{~mm}$. An electrically insulated target connected to an electrometer that measures the depleted charge periodically would serve as a halo intensity monitor.

Table 1. Maximum Scraping Rate at a Scraper for 250 Collider Fills per Year with $1.3 \times 10^{14}$ Protons per Fill [9].

\begin{tabular}{|c|c|c|c|l|}
\hline Energy (TeV) & Duration & Rate $(p / s)$ & Annual $(p / y r)$ & Cycle Stage \\
\hline 2 & $0.1-1 \mathrm{~s}$ & $1.3 \times 10^{12}$ & $3.25 \times 10^{14}$ & $\begin{array}{l}\text { Beginning of } \\
\text { acceleration }\end{array}$ \\
\hline 20 & $15 \mathrm{~min}$ & $3.0 \times 10^{9}$ & $6.75 \times 10^{14}$ & $\begin{array}{l}\text { Beginning of } \\
\text { flattop before } \\
\text { collisions }\end{array}$ \\
\hline 20 & $24 \mathrm{~h}$ & $4.0 \times 10^{8}$ & $8.64 \times 10^{15}$ & Collisions \\
\hline
\end{tabular}




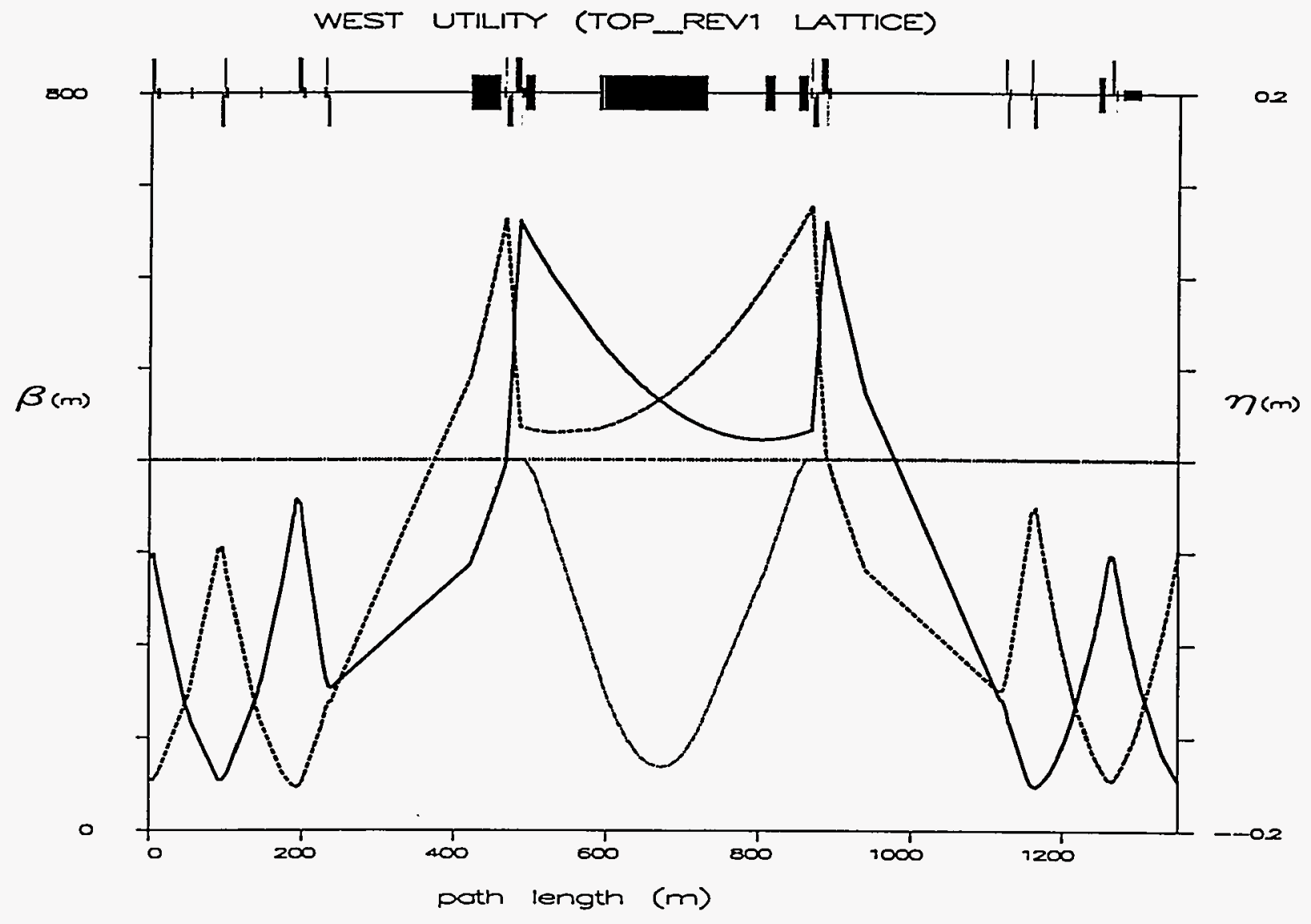

Fig. 11. Lattice functions in the West Utility Region. 
Table 2. Summary of Types and Numbers of Scrapers and Collimators.

\begin{tabular}{|c|c|c|c|}
\hline Name & Description & $\begin{array}{l}\text { aw Length } \\
\text { (m) }\end{array}$ & Shielding \\
\hline SCRHWUT & Horizontal Scraper - Top Ring & 1.2 & $0.65 \times 4.5 \mathrm{~m}$ \\
\hline SCRVWUT & Vertical Scraper - Top Ring & 1.2 & \\
\hline SCRHWUB & Horizontal Scraper - Bottom Ring & 1.2 & $0.65 \times 4.5 \mathrm{~m}$ \\
\hline SCRVWUB & Vertical Scraper - Top Ring & 1.2 & \\
\hline CHWUT1 & Horizontal - Top Ring, Warm Abort Dipole & 2.8 & $0.35 \times 4.5 \mathrm{~m}$ \\
\hline CHWUT2 & Horizontal - Top Lambertson Magnet & 2.8 & $0.35 \times 4.5 \mathrm{~m}$ \\
\hline CHTIT & Horizontal - Top Hinge & 2.8 & $0.35 \times 4.5 \mathrm{~m}$ \\
\hline CHWUB1 & Horizontal - Bottom Ring, Warm Abort Dipole & 2.8 & $0.35 \times 4.5 \mathrm{~m}$ \\
\hline CHWUB2 & Horizontal - Bottom Lambertson Magnet & 2.8 & $0.35 \times 4.5 \mathrm{~m}$ \\
\hline CHTIB & Horizontal - Bottom Hinge & 2.8 & $0.35 \times 4.5 \mathrm{~m}$ \\
\hline CVENIRT & Vertical - Top Ring, E-N IR, BV1M & 2.8 & $0.35 \times 4.5 \mathrm{~m}$ \\
\hline CVESIRT & Vertical - Top Ring, E-S IR, BV1P & 2.8 & $0.35 \times 4.5 \mathrm{~m}$ \\
\hline CVESIRB & Vertical - Bottom Ring, E-S IR, BV1M & 2.8 & $0.35 \times 4.5 \mathrm{~m}$ \\
\hline CVENIRB & Vertical - Bottom Ring, E-N IR, BV1P & 2.8 & $0.35 \times 4.5 \mathrm{~m}$ \\
\hline CLWUT1 & L-collimator - Top Ring, Dogleg Dipole & 2.8 & $0.35 \times 4.5 \mathrm{~m}$ \\
\hline CLWUB1 & L-collimator - Bottom Ring, Dogleg Dipole & 2.8 & $0.35 \times 4.5 \mathrm{~m}$ \\
\hline CLENIRT & L-collimator - Top Ring, E-N IR, BV1CM & 2.8 & $0.35 \times 4.5 \mathrm{~m}$ \\
\hline CLESIRT & L-collimator - Top Ring, E-S IR, BV1CP & 2.8 & $0.35 \times 4.5 \mathrm{~m}$ \\
\hline CLENIRB & L-collimator - Bottom Ring, E-N IR, BV1CP & 2.8 & $0.35 \times 4.5 \mathrm{~m}$ \\
\hline CLESIRB & L-collimator - Bottom Ring, E-S IR, BV1CM & 2.8 & $0.35 \times 4.5 \mathrm{~m}$ \\
\hline CGWUT1 & Graphite Collimator - Top Ring, QSD1 & 2.8 & No \\
\hline CGWUT2 & Graphite Collimator - Top Ring, Dogleg Dipole & le 5.0 & $0.35 \times 5.5 \mathrm{~m}$ \\
\hline CGWUB1 & Graphite Collimator - Bottom Ring, QSD1 & 2.8 & No \\
\hline CGWUB2 & Graphite Collimator - Bottom Dogleg Dipole & 5.0 & $0.35 \times 5.5 \mathrm{~m}$ \\
\hline CFENIR1 & Fixed Aperture - East North IR & 3.0 & $0.75 \times 4.0 \mathrm{~m}$ \\
\hline CFENIR2 & Fixed Aperture - East North IR & 3.0 & $0.75 \times 4.0 \mathrm{~m}$ \\
\hline CFESIR 1 & Fixed Aperture - East South IR & 3.0 & $0.75 \times 4.0 \mathrm{~m}$ \\
\hline CFESIR2 & Fixed Aperture - East South IR & 3.0 & $0.75 \times 4.0 \mathrm{~m}$ \\
\hline CFENIR1 & Neutral Beam Dump - East North IR & 2.0 & $0.65 \times 3.0 \mathrm{~m}$ \\
\hline CFENIR2 & Neutral Beam Dump - East North IR & 2.0 & $0.65 \times 3.0 \mathrm{~m}$ \\
\hline CFESIR1 & Neutral Beam Dump - East South IR & 2.0 & $0.65 \times 3.0 \mathrm{~m}$ \\
\hline CFESIR2 & Neutral Beam Dump - East South IR & 2.0 & $0.65 \times 3.0 \mathrm{~m}$ \\
\hline SSWUT & Shadow Septum - Top Ring Lambertson & 5.0 & $0.35 \times 5.5 \mathrm{~m}$ \\
\hline SSWUB & Shadow Septum - Bottom Ring Lambertson & 5.0 & $0.35 \times 5.5 \mathrm{~m}$ \\
\hline
\end{tabular}


Table 3. Power (kW) Deposited in System Components.

\begin{tabular}{|l|l|c|c|}
\hline Component & $2 \mathrm{TeV}(1 \mathrm{~s})$ & $20 \mathrm{TeV}$, Peak $(15 \mathrm{~min})$ & $20 \mathrm{TeV}(24 \mathrm{~h})$ \\
\hline Target & 0.03 & 0.0001 & 0.000013 \\
Scraper & 210 & 4.1 & 0.530 \\
SSWUT & 42 & 0.82 & 0.110 \\
CGWUT2 & 36 & 0.70 & 0.090 \\
Collimators 1 & 20 & 0.40 & 0.050 \\
Collimators 2 & 10 & 0.20 & 0.025 \\
\hline
\end{tabular}

Scraper. Because of high energy deposition, the scraper jaws are made of copper. A transient 3-D finite element model was developed [10] to perform a thermal analysis of the scraper at the peak scraping rate of table 1. The temperature-dependent thermo-physical properties of copper were accounted for. Conducting the heat from the scraping surface to the coolant is crucial to keeping the whole surface flat within a few microns. A water cooling system with two 13-mm-diameter channels spacing $25 \mathrm{~mm}$ from the scraping surface at a rate of about 5 liters per minute per channel would keep the peak temperature rise below $25^{\circ} \mathrm{C}$, providing the lateral expansion within the required limits of table $4 . \mathrm{A}$ closed-loop chilled water system would be required because of the high levels of radiation generated by the beam-scraper interactions. Another design compatible with an even higher scraping rate has been proposed to use copper with embedded high-conductivity carbon fibers to conduct the heat. Along the fibers the heat conductivity is about 5 times that of copper.

Table 4. Technical Requirements to Jaws ( \pm ).

\begin{tabular}{|c|c|c|}
\hline Parameter & Scraper & Collimator \\
\hline Smoothness of beam side surface $(\mathrm{mm})$ & 5 & 50 \\
Tilt accuracy tolerance $(\mathrm{mrad})$ & $5-10$ & $50-100$ \\
Thermal lateral deflection $(\mathrm{mm})$ & 5 & 20 \\
Positioning accuracy tolerance $(\mathrm{mm})$ & 5 & 50 \\
\hline
\end{tabular}

Collimators. Collimator jaws in general are made of steel and in most cases do not require any cooling. Standard low-conductivity water (LCW) supply would be used to cool collimator jaws that require cooling. Very low quantities of LCW would be used for this purpose. Therefore, LCW could come off of pre-existing LCW headers. During 
asynchronized abort, in which the beam is sprayed across from the closed orbit to the abort direction, the Lambertson magnet septum and the steel collimator downstream could be melted. To protect them from such a possibility, a 5-m-long shadow Lambertson made of graphite and a 5-m-long collimator jaw to shadow the downstream steel unit are required.

As mentioned above, the alignment requirements in our design are significantly relaxed compared to the two-stage collimator scheme. It was found in [2] and in recent, more realistic simulations that the overall alignment tolerance is $\pm(10-15) \mu \mathrm{m}$, or about $\pm 10 \mu \mathrm{rad}$ for the SSC scrapers and $\pm 100 \mu \mathrm{m}$ for the collimators. Summary of the corresponding technical requirements to scraper and collimator jaws is given in table 4. Movable jaws are controlled by high-precision motors. The full range of the transverse movement is $20 \mathrm{~mm}$. The scattering targets, scrapers, and collimator jaws are fixed in their longitudinal positions. Each target and the ends of each scraper would be independently movable. Additionally, the target/scraper assembly would be movable as a single unit in both horizontal and vertical planes with respect to the upstream beam position monitor. Eight dipole corrector magnets are used for final fine tuning of the beam with the scrapers. With the $50-\mu \mathrm{m}$ target/scraper offset, it is essential that the whole system-consisting of the upstream beam position monitor, target, and scraper jaw-be bench aligned to within 10 $\mu \mathrm{m}$ before installation. Targets would remain electrically insulated at all times, including during their motion, except for times of measurement, during which the circuit grounds the targets periodically.

A high-precision feedback system using real-time data from the beam position monitors and the beam loss monitors positioned upstream and immediately downstream of the scrapers will be used to control the scraping rate. Should the beam loss monitor reading exceed a predetermined amount, the system would automatically back the targets and scraper jaws away from the beam to maintain a scraping rate that is consistent with the predetermined beam loss level. As a precautionary measure to avoid accidents, the control 
system would also have an interlock mechanism to stop forward movement of the scraper, collimator, or target if the beam loss monitor downstream reads above a preset threshold value. However, the interlock system should allow manual or programmed withdrawal of the scraper, collimator, or target from this preset position.

In addition, the target/scraper assembly must be instrumented to monitor the temperature of the scraper and coolant at inflow and outflow points and the flow rate of the coolant. Instrumentation for measuring the positions of the targets, scrapers, and collimators with respect to reference points is also required. The jaws are surrounded with radiation shielding. Corresponding lengths and thicknesses of steel shielding are presented in table 2. In a few cases some amount of a hydrogenous material is required outside the steel.

\section{IR collimators}

A set of collimators is required in the East IRs to protect the final focus triplet and vertical bending magnets (fig. 12). The set consists of 10 collimators with movable jaws and 4 collimators with fixed aperture. Optimal jaw position for the first group is $20 \sigma$ from the circulating beam axis. Four collimators with fixed aperture of $25-\mathrm{mm}$-ID protect first low- $\beta$ quads against intense radiation from the interaction points (IP). Each collimator has a 2.8-m-long steel jaw surrounded with radiation shielding.

The fixed-aperture collimators CFENIR and CFESIR are placed in the experimental halls just upstream of the low- $\beta$ quadrupoles. Other collimators intercept high-energy protons (mainly diffractive) produced by beam interactions all around the machine. Collimators CLENIRT and CLESIRT are used to intercept secondaries produced by local beam-gas interactions. For each ring, one collimator (CLENIRT) is situated upstream of the IP and one (CVENIRT) downstream of the IP; this is just downstream of the common vertical bending magnets. Collimator CHTIT is placed in the middle of the hinge region at a non-zero dispersion point. Collimator jaw positions at injection and top energies are shown in table 5. 


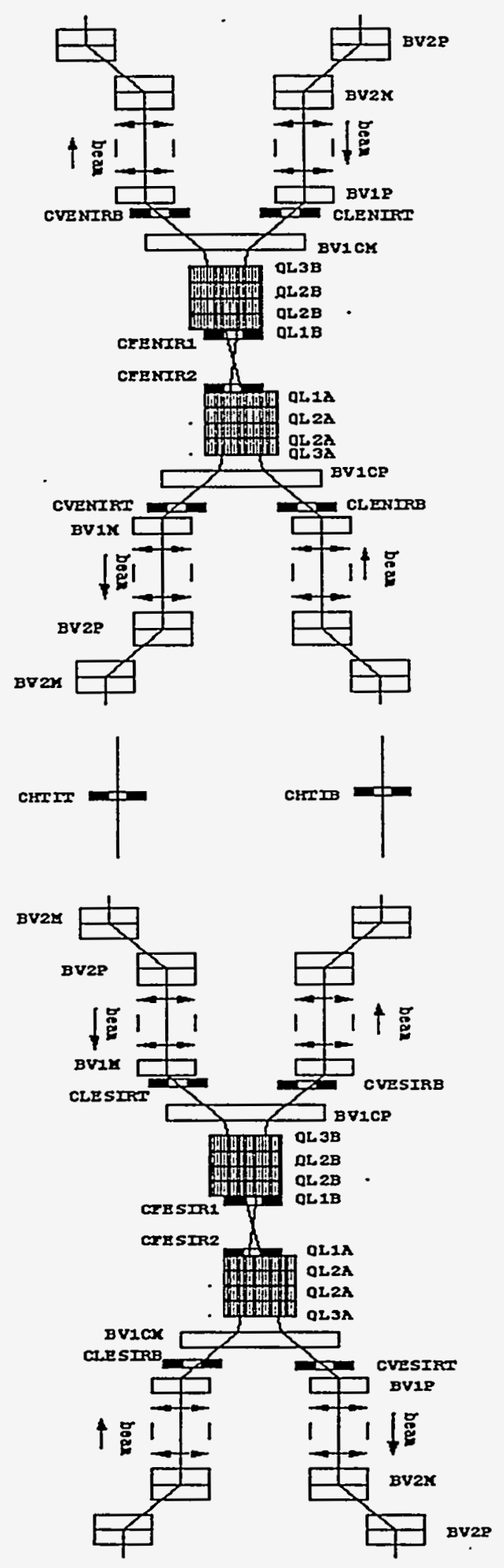

Fig. 12. Collimator positions in the East Interaction Regions. 
Table 5. Lattice Functions, Scraper and Collimator Locations (S) and Positions $(\Delta)$ with Respect to Beam Axis at Injection andTop Energies. $S=0$ at the Center of the West Utility.

\begin{tabular}{|l|r|r|r|r|r|r|r|}
\hline Name & $\mathrm{S}(\mathrm{m})$ & $\beta_{\mathrm{x}}(\mathrm{m})$ & $\beta_{\mathrm{y}}(\mathrm{m})$ & \multicolumn{2}{c|}{\begin{tabular}{c} 
Injection: \\
\multicolumn{1}{|c|}{}
\end{tabular}} & & \multicolumn{2}{c|}{$\begin{array}{c}\text { Injection: } \\
\mathrm{x}(\mathrm{mm})\end{array}$} & \multicolumn{2}{c|}{$\begin{array}{c}\text { Collisions: } \\
\Delta_{\mathrm{y}}(\mathrm{mm})\end{array}$} & \multicolumn{2}{c|}{$\begin{array}{c}\Delta_{\mathrm{x}}(\mathrm{mm}) \\
\Delta_{\mathrm{y}}(\mathrm{mm})\end{array}$} \\
\hline SCRHWUT & -156.4 & 611 & 430 & -5.4 & & -1.7 & \\
SCRVWUT & -154.9 & 609 & 430 & & -4.5 & & -1.4 \\
CHWUT1 & 120.6 & 422 & 584 & 7.1 & 8.4 & 2.8 & 3.3 \\
CLWUT1 & 149.4 & 423 & 621 & -7.1 & -8.7 & -2.8 & -3.4 \\
CHWUT2 & 259.3 & 480 & 287 & 7.5 & & 3.0 & \\
CLENIRT & 37436 & 4108 & 1554 & -6.2 & -4.1 & -8.9 & -5.5 \\
CFENIR1 & 37600 & 799 & 791 & 12.5 & 12.5 & 12.5 & 12.5 \\
CFENIR2 & 37638 & 799 & 793 & 12.5 & 12.5 & 12.5 & 12.5 \\
CVENIRT & 37843 & 1007 & 2605 & & -5.2 & & -7.0 \\
CHTIT & 38864 & 103 & 174 & -3.5 & & -1.4 & \\
CLESIRT & 39956 & 4097 & 1591 & -6.2 & -4.1 & -8.9 & -5.5 \\
CFESIR1 & 40120 & 796 & 812 & 12.5 & 12.5 & 12.5 & 12.5 \\
CFESIR2 & 40158 & 797 & 812 & 12.5 & 12.5 & 12.5 & 12.5 \\
CVESIRT & 40363 & 1001 & 2675 & & 5.2 & & 7.0 \\
\hline
\end{tabular}

Having no other collimators in the IRs but CFENIR and CFESIR, maximum beam loss in superconducting magnets due to $p p$-collisions is about $2 \times 10^{5} \mathrm{p} / \mathrm{m} / \mathrm{s}$ (fig. 13). Added to other sources, this exceeds any possible limits. With the appropriate collimators at $20 \sigma$, calculated beam loss distribution in the IRs is shown in fig. 14. Beam loss rate is decreased to about $6 \times 10^{3} \mathrm{p} / \mathrm{m} / \mathrm{s}$ at all IR superconducting magnets. Most of this loss is intercepted by CVENIRT and CVESIRT collimators.

It turns out that the IR collimators can't completely protect the $\beta$-peak region against protons outscattered from the scrapers. Beam loss distribution due to that component, calculated with and without collimators, is shown in figs. 15 and 16, respectively. Even with the collimators on, beam loss rate in the QL3 quads is unacceptably high. The solution, as described in previous sections, is three additional collimators in the West Utility downstream of the abort Lambertson magnets. They provide good interception of most protons escaping from the scraper. 


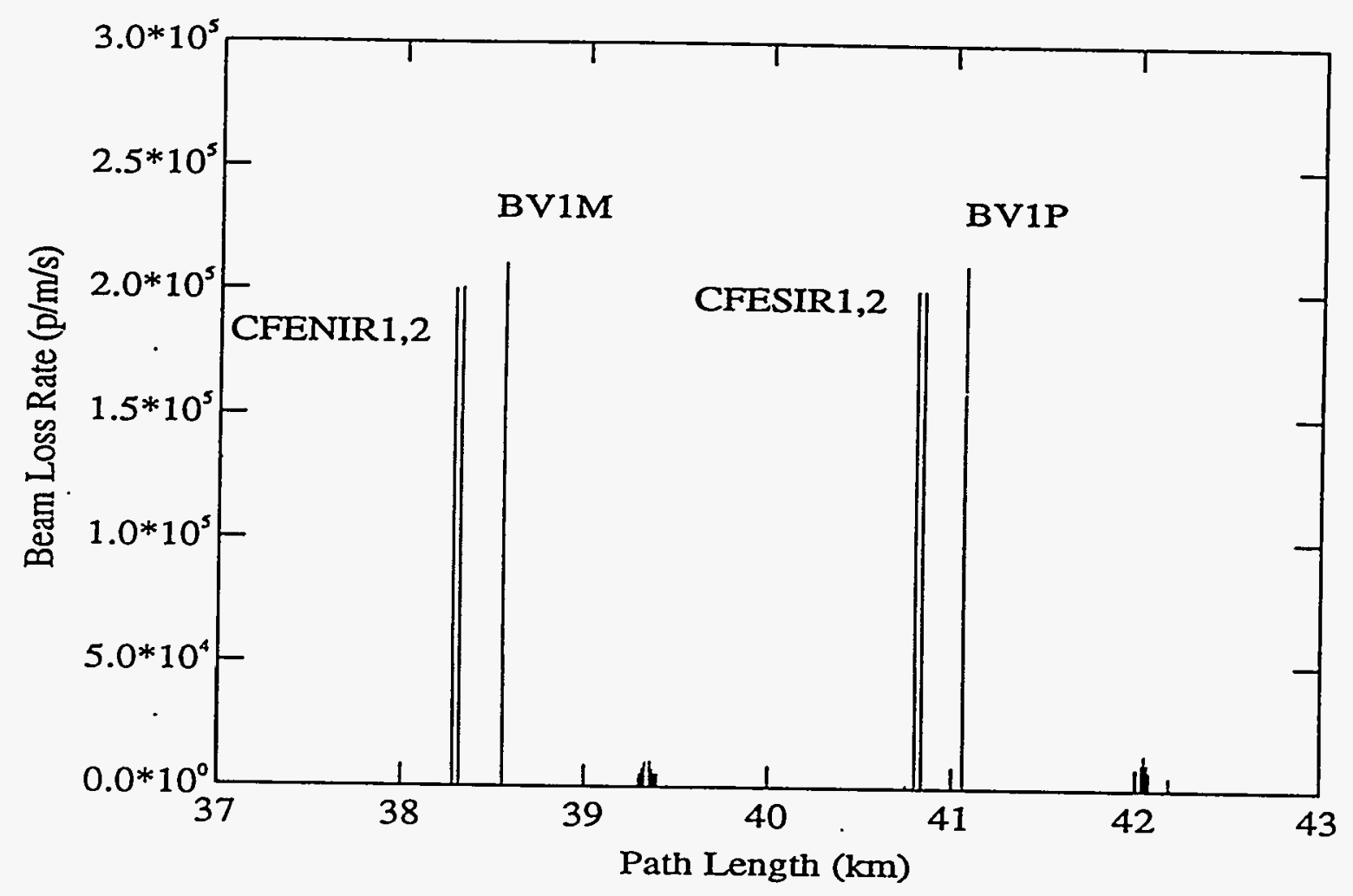

Fig. 13. Beam loss rate in superconducting magnets due to $p p$-collisions, with no collimators in the IRs.

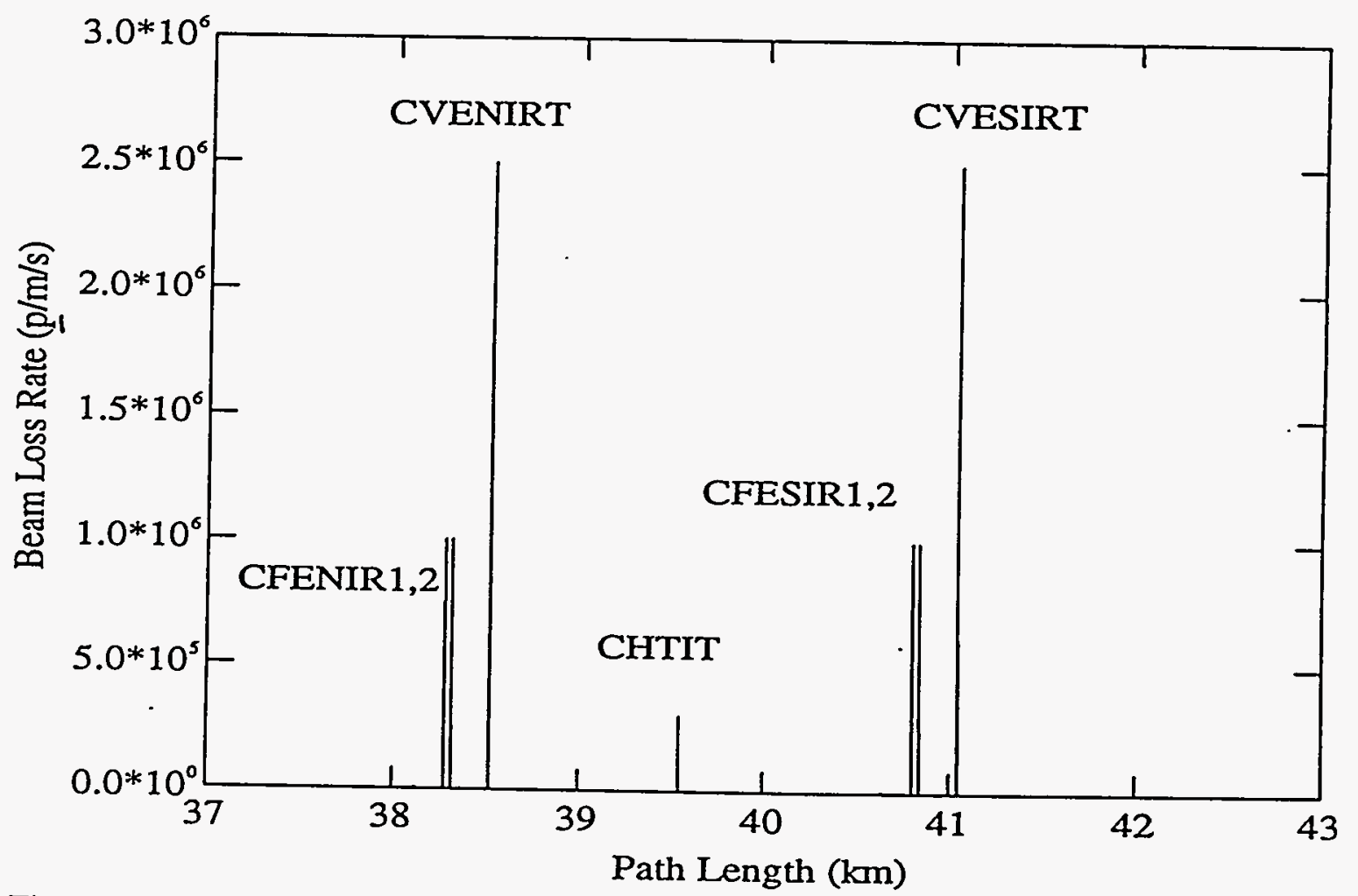

Fig. 14. Beam loss rate in superconducting magnets due to $p p$-collisions, with collimators in the IRs. 


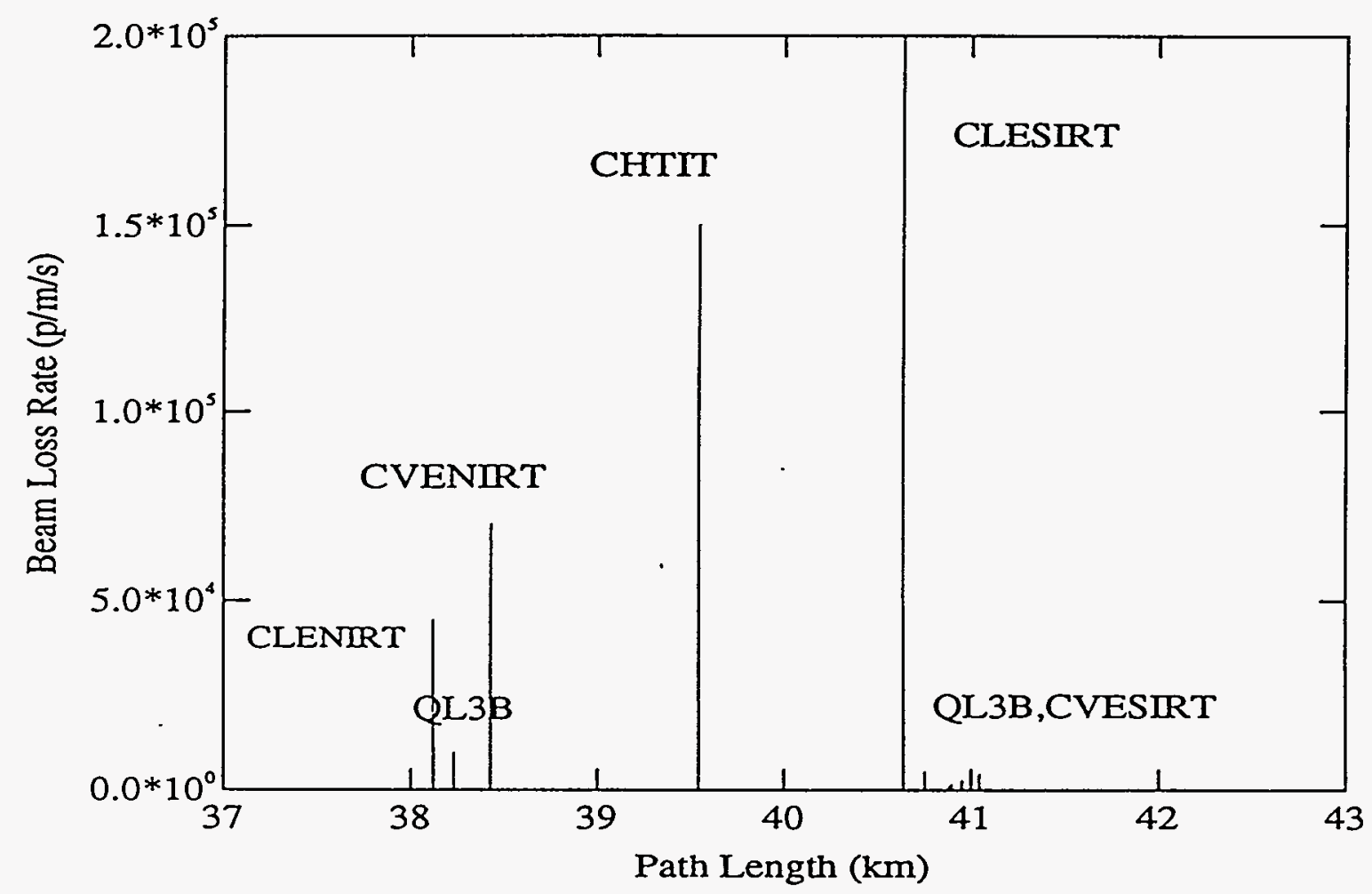

Fig. 15. Beam loss distribution due to scraping, calculated with collimators in IR.

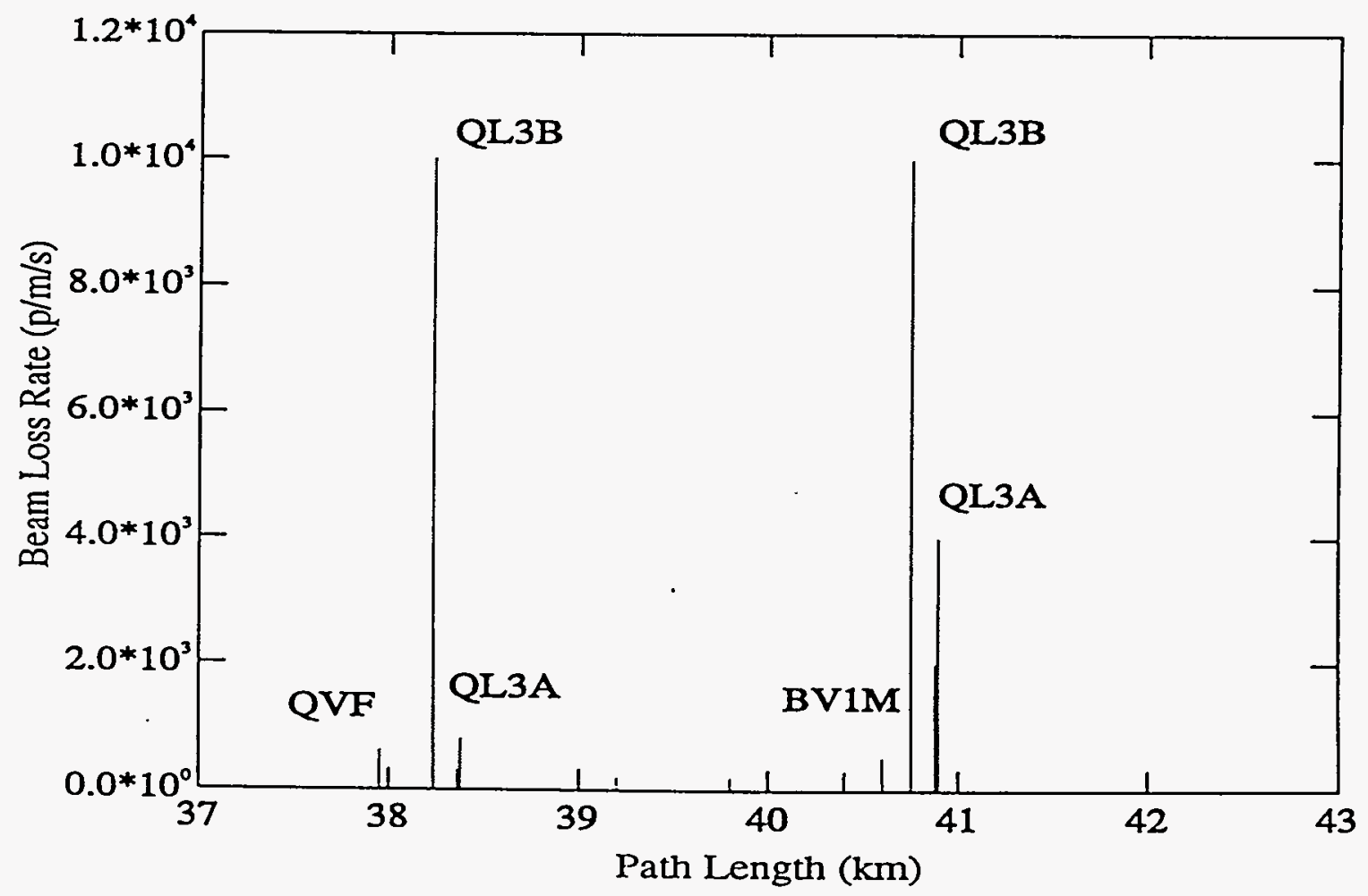

Fig. 16. Beam loss distribution due to scraping, calculated with no collimators in IR. 
Counterclockwise collimation (bottom Collider ring) is slightly different from the top ring collimation because of the different phase advance between the scraper and the IRs. Therefore, beam loss distribution shown in fig. 17 is also slightly different. The high loss rate in the West IR quads is due to absence of collimators in this region. So, one needs to have the same set of collimators in the West IR that is assumed for the East IR in case of low- $\beta$ in the West cluster.
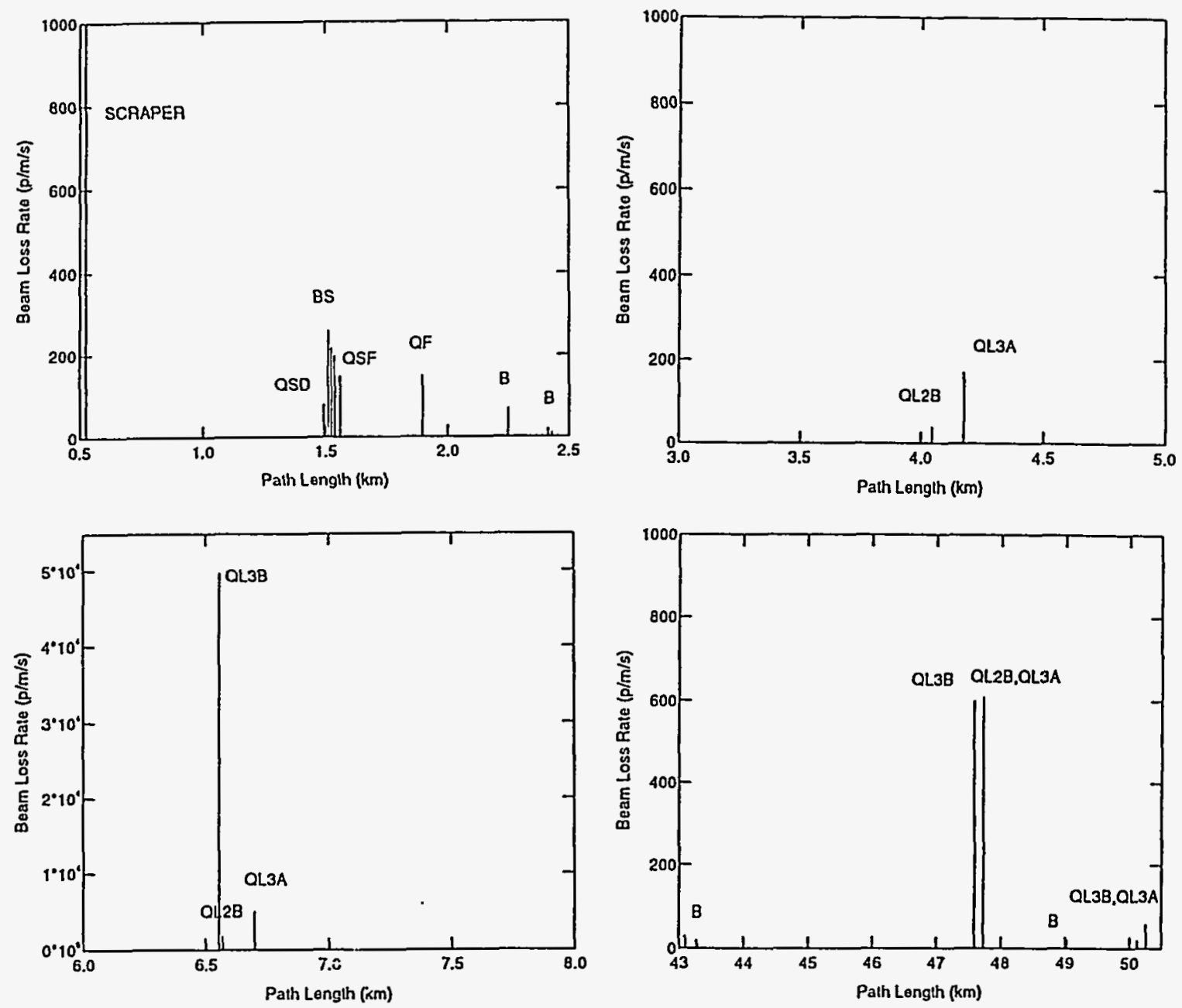

Fig. 17. Beam loss distribution for the Collider, counterclockwise direction. 


\section{East utility scraping}

The described scraper/collimator system is sufficient to protect Collider equipment from irradiation. But zero dispersion in the West Utility doesn't provide an opportunity to clean the beam from off-momentum particles. Therefore, a matching lattice with non-zero dispersion was considered in the East Utility for off-momentum scraping, as shown in fig. 18. The $\beta$-function is almost the same as that in the West Utility, but the dispersion (see fig. 18) is equal to $2 \mathrm{~m}$. The main purpose of the scraper system in the East Utility is to clean the beam of off-momentum particles, as shown in fig. 19. This scheme is the same as that shown for the West Utility, but the dogleg is much simpler and cheaper. It consists of eight resistive 1-T, 6-m-long dipoles. The same scheme can be used for slow extraction of the beam with bent crystals.

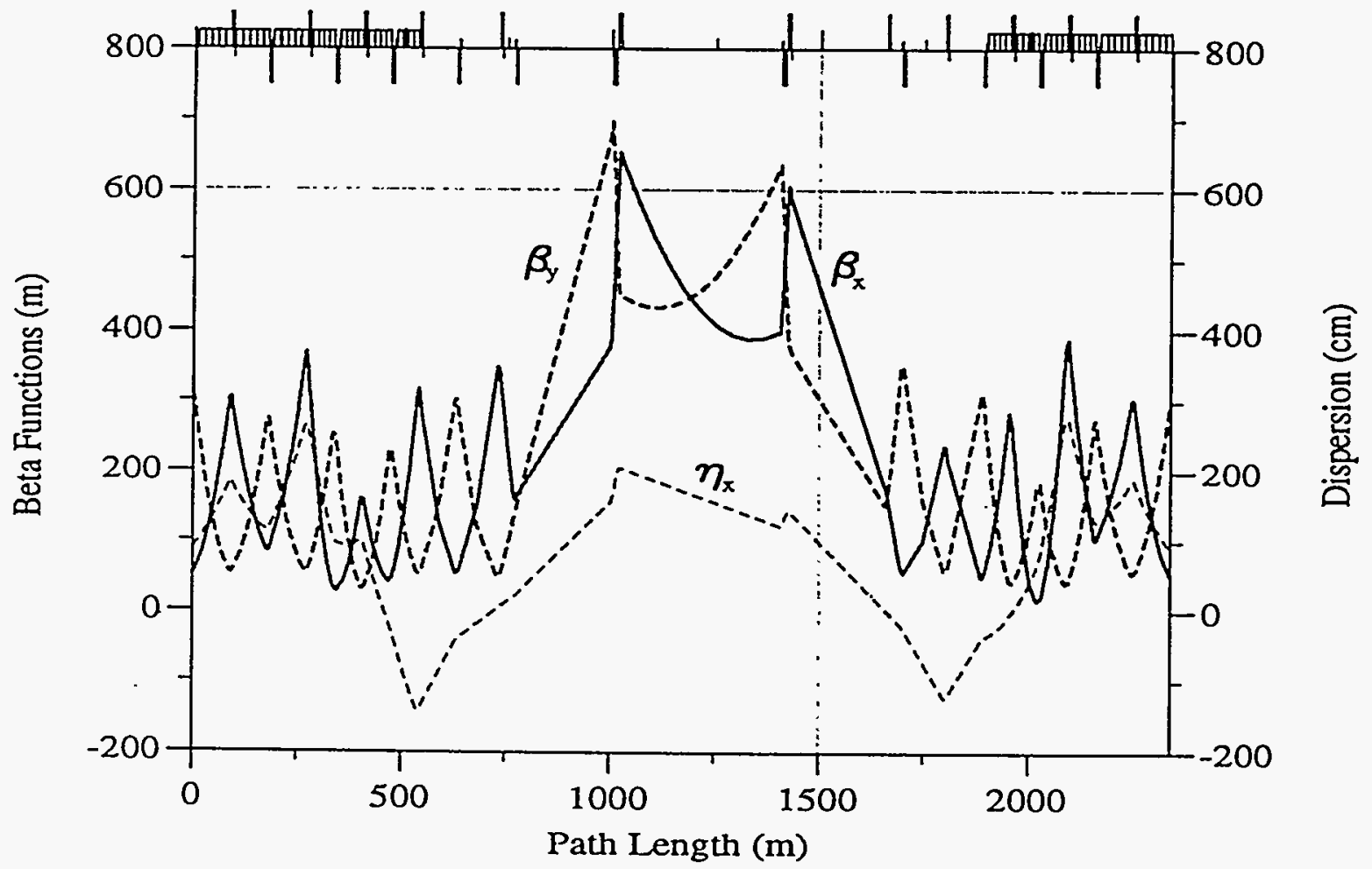

Fig. 18. Lattice functions in the East Utility. 


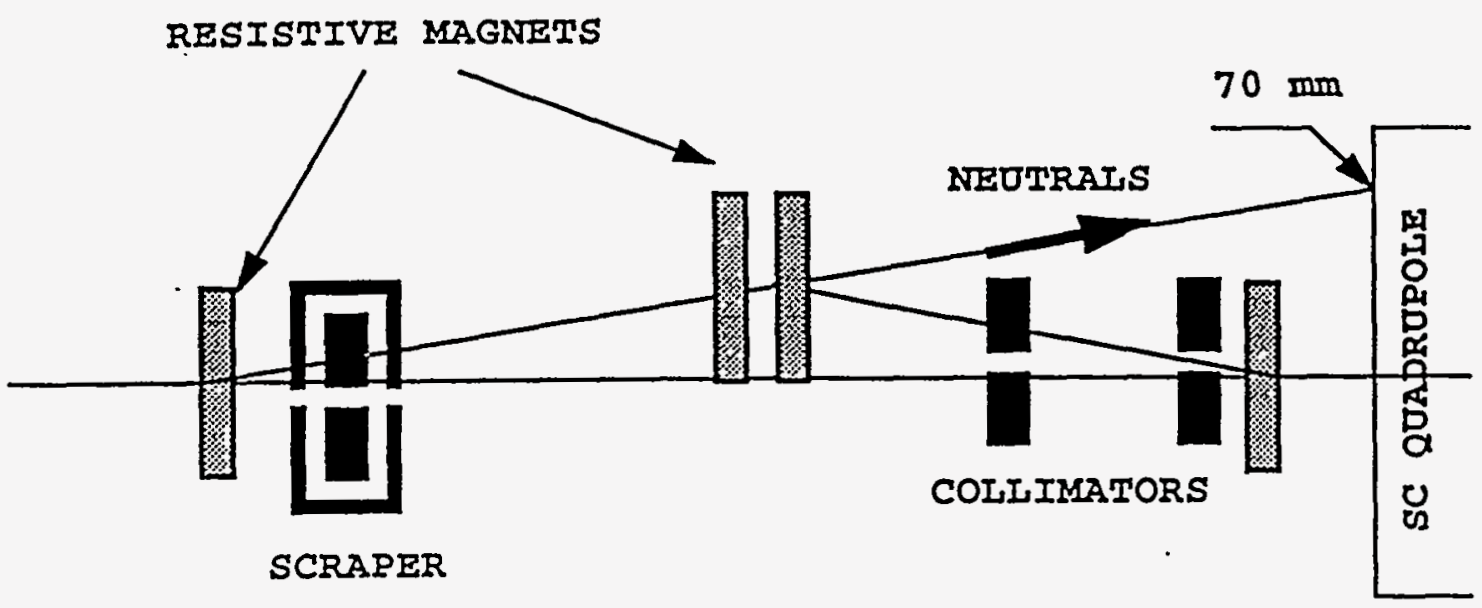

Fig. 19. Principal scheme of beam cleaning for off-momentum protons in the East Utility.

\section{Cost}

To eliminate redundant engineering cost, the designs for High Energy Booster (HEB) and Collider scrapers and collimators should be done in parallel, because the effect and consequences of beam-scraper interaction are practically the same at 2 and $20 \mathrm{TeV}$. Therefore, this would be a shared cost for all collimators and scrapers in the HEB and Collider. Thus, it was agreed to use a 2.8-m-long L-shaped jaw for all collimators in both accelerators. Reliability and subsystem impact issues were also considered. A cost estimate for the HEB and Collider scraper/collimation systems was put through the value engineering process. For the Collider, the final cost estimate for the system engineering design is $\$ 1.103 \mathrm{M}$; for procurement, assembly, fabrication, transit, installation, and test the estimate is $\$ 7.174 \mathrm{M}$. The shielding cost is $\$ 3.998 \mathrm{M}$, leading to a grand total of $\$ 12.275 \mathrm{M}$ for the Collider system. For the HEB the corresponding cost is estimated at $\$ 1.993 \mathrm{M}$. 


\section{Conclusions}

We have designed the beam collimation system, consisting of a scattering target and associated scraper followed by a few collimators, which is compatible with high-intensity proton beams of the $\mathrm{TeV}$ energy region. The design is based on the realistic Monte Carlo simulation of beam halo formation, proton interactions with the target and scraper, particle tracking in the machine, shower simulations at the beam loss points, thermal analysis, and engineering optimization. We have studied in detail the associated cooling mechanism, alignment possibilities, and control issues and have justified the technical requirements. Overall, the proposed system is very efficient, technically feasible, cost effective, and usable at superconducting proton accelerators to be upgraded or to be built. We wish to thank people who were involved in the consideration of this system at various stages: H. Edwards, M. Maslov, I. Yazynin, I. Baishev, B. Dao, R. Meinke, B. Parker, D. Ritson, and N. Tran. 


\section{References}

[1] I. Baishev, A. Drozhdin, and N. Mokhov, "Beam Loss and Radiation Effects in the SSC Lattice Elements," SSCL-306 (1990).

[2] M. Maslov, N. Mokhov, and I. Yazynin, "The SSC Beam Scraper System," SSCL-484 (1991).

[3] I. Baishev, A. Drozhdin, and N. Mokhov, "Beam Loss Handling at the SSC," SSCL-Preprint-328, (1993); Proc. of IEEE Particle Accelerator Conference, p. 3109 (1993).

[4] A. Drozhdin, I. Baishev, N. Mokhov, B. Parker, R. Richardson, and J. Zhou, "Dealing with Abort Kicker Prefire in the Superconducting Super Collider," SSCL-Preprint-329 (1993); Proc. of EEE Particle Accelerator Conference, p. 3772 (1993).

[5] N. Mokhov, "MARS12 Code System," Proc. SARE Workshop, Santa Fe (1993); N.Mokhov, "MARS10 Code System User's Guide," Fermilab FN-509 (1989).

[6] I. Baishev, A. Drozhdin, and N. Mokhov, "STRUCT Code User's Reference Manual," SSCL-MAN-0034 (1994).

[7] ANSYS Engineering Analysis System, Revision 4.4, Swanson Analysis Systems, Inc., Houston, Pennsylvania (1989).

[8] L. Burnod, J.B. Jeanneret, "Beam Losses and Collimation in the LHC: A Quantitative Approach," CERN SL/91-39 (1991).

[9] Collider 3B Specifications, E10-000073, SSCL (1993).

[10] N. Tran, B. Dao, "Thermal Analysis of the SSC Beam Scraper," SSCL-Preprint-308 (1993). 